\title{
PRELIMINARY INVESTIGATION OF THE POSSIBILITY FOR IMPLEMENTATION OF MODIFIED PHARMACOPOEIAL HPLC METHODS FOR QUALITY CONTROL OF METRONIDAZOLE AND CIPROFLOXACIN IN MEDICINAL PRODUCTS USED IN VETERINARY MEDICINE
}

\author{
Marjan Piponski, Tanja Bakovska, Marina Naumoska, Tatjana Rusevska, \\ Gordana Trendovska Serafimovska, Hristina Andonoska \\ Pharmaceutical Company Replek Farm Ltd., Quality Control Department \\ st. Kozle 188, 1000 Skopje
}

Received 3 June 2014; Received in revised form 25 September 2014; Accepted 10 November 2014

\begin{abstract}
Quality control of veterinary medicine products containing two different frequently used antibiotics metronidazole and ciprofloxacin hydrochloride, was considered and performed, using modified pharmacopoeial HPLC methods. Three different HPLC systems were used: Varian ProStar, Perkin Elmer Series and UPLC Shimadzu Prominence XR. The chromatographic columns used were LiChropher RP Select B $75 \mathrm{~mm}$ x $4 \mathrm{~mm}$ with $5 \mu \mathrm{m}$ particles and Discovery C18 $100 \mathrm{~mm}$ x 4,6 mm with $5 \mu \mathrm{m}$ particles. Chromatographic methods used for both analytes were compendial, with minor modifications made for experimental purposes. Minor modifications of the pharmacopoeia prescribed chromatographic conditions, in both cases, led to better chromatographic parameters, good resolution and shorter analysis times. Optimized methods can be used for: determination of metronidazole in gel formulation, for its simultaneous quantification with preservatives present in the formulation and even for identification and quantification of its specified impurity, 2-methyl-5-nitroimidazole; determination of ciprofloxacin hydrochloride in film coated tablets and eye drops and identification and quantification of its specified impurities. These slightly modified and optimized pharmacopoeial methods for quality control of metronidazole and ciprofloxacin dosage forms used in veterinary medicine can be successfully applied in laboratories for quality control of veterinary medicines.
\end{abstract}

Key words: metronidazole, ciprofloxacin hydrochloride, veterinary medicines, pharmacopoeia, quality control

\section{INTRODUCTION}

We considered and performed quality control of two different antibiotics used in human and veterinary medicine, metronidazole and ciprofloxacin hydrochloride, which are frequently used worldwide. Metronidazole (Fig. 1a) is a nitroimidazole antibiotic used for prevention and treatment of bacterial and parasitic infections in animals and is usually administered as tablet, capsule, oral liquid or injectable or is topically applied as gel, cream or ointment. It is not intended for use in food producing animals, i.e. according to EU Regulation 37/2010 it is a prohibited substance (1).

Corresponding author: Marjan Piponski, $\mathrm{PhD}$

E-mail address: piponski@yahoo.com

Present address: Replek Farm Ltd., Quality Control Department

st. Kozle 188, Skopje, Republic of Macedonia

Phone: + 38971246233

Copyright: (C) 2015 Piponski M. This is an open-access article published under the terms of the Creative Commons Attribution License which permits unrestricted use, distribution, and reproduction in any medium, provided the original author and source are credited.

Competing Interests: The authors have declared that no competing interests exist.

Available Online First: 17 November 2014

http://dx.doi.org/10.14432/j.macvetrev.2014.11.029
Ciprofloxacin hydrochloride (Fig. 1b) is a secondgeneration fluoroquinolone antibiotic used for treatment of bacterial infections in animals and is administered as injectable, oral liquid, tablet, capsule and eye or ear medication $(2,3)$. Both antibiotics are also used in human medicine.

Quality control of veterinary medicines is regulated by various directives (such as Directive 2001/82/EC and 2004/28/EC of the European Parliament and of the Council) $(4,5,6)$ and guidelines (such as European Medicine Agency - EMEA guidelines for specific veterinary dosage forms) $(6,7)$. Methods used for quality control of veterinary medicines can be found in specific medicine monographs listed in Veterinary pharmacopoeias (which usually are companion volumes to pharmacopoeias), such as British Pharmacopoeia (Veterinary) (8), China Veterinary Pharmacopoeia (9), Indian Pharmacopoeia Veterinary (10) etc. If there is not an official monograph in veterinary pharmacopoeias for some drug product used in veterinary medicine, its quality can be controlled according to the monographs 
a)<smiles>Cc1ncc([N+](=O)[O-])n1CCO</smiles>

b)

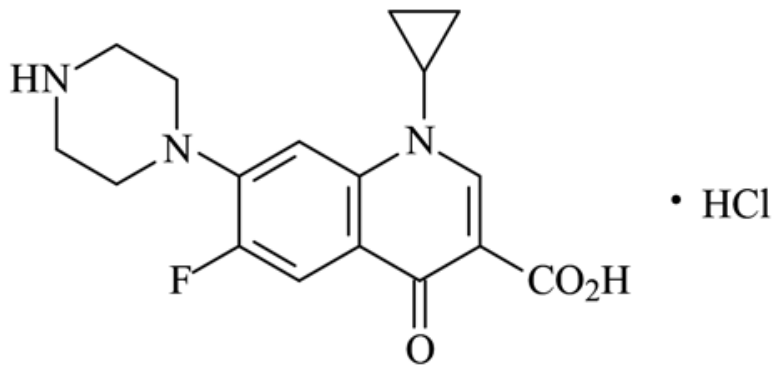

Figure 1. Structural formulas of: a) metronidazole and b) ciprofloxacin hydrochloride

given in European Pharmacopoeia (11), British Pharmacopoeia (12), United States Pharmacopoeia (13), Japanese Pharmacopoeia (14), International Pharmacopoeia (15) etc., or with some other new, completely validated analytical methods developed especially for this purpose.

Metronidazole is included in the British Pharmacopoeia (Veterinary) 2012 with a full monograph, which includes sample preparation, method for quality control and propositions for quality interpretation. Ciprofloxacin hydrochloride is not covered by the British Pharmacopoeia (Veterinary) 2012, but has a monograph in the main part of the British Pharmacopoeia 2012. In our investigation we used the method for assay determination of ciprofloxacin hydrochloride given in the BP monograph, with slight methodological modifications.

The aim of this work was to investigate the quality of some veterinary medicinal preparations containing metronidazole and ciprofloxacin hydrochloride, which can be purchased in Macedonia and to check the compliance of the obtained results with the compendial requirements of the respective drug monographs.

Also, our general aim was to investigate the possibility for implementation of improved, more rapid and more reliable procedures for quality control of the above mentioned veterinary medicinal products.

\section{MATERIAL AND METHODS}

In this research three different HPLC system were used:

- Varian ProStar with ternary high pressure mixing pump, autosampler 410 with column oven and Photo Diode Array detector 330, controlled by software Varian-Star Version 6.31;

- Perkin Elmer Series 200 with autosampler, Photo Diode Array detector, column oven and quaternary pump controlled by TotalChrom software;

- UPLC Shimadzu Prominence XR with quaternary pump, autosampler, Photo Diode Array detector, column oven and controller, controlled by Lab Solutions software.

The chromatographic columns used on these HPLC systems were: LiChropher RP Select B $75 \mathrm{~mm}$ x $4 \mathrm{~mm}$ with $5 \mu \mathrm{m}$ particles (Merck Darmstadt, Germany) and Discovery C18 100 mm x 4,6 mm with $5 \mu \mathrm{m}$ particles (Supelco Bellefonte, USA).

All used chemicals were of Ph.Eur. grade: methanol, acetonitrile, trifluoroacetic acid, $85 \%$ o-phosphoric acid, ammonium dihydrogen phosphate and triethylamine, all purchased from Merck Darmstadt, Germany. The demineralized water was an in-house product with conductivity of less than $2 \mu \mathrm{S} / \mathrm{cm}$. Working standards for active substances (metronidazole working standard with potency $99,6 \%$ and ciprofloxacin hydrochloride working standard with potency 99,8 \%, both standardized using referent standards purchased from European Pharmacopoeia), Metronidazole gel $0,75 \%$ and Ciprofloxacin film coated tablets $500 \mathrm{mg}$ were purchased from the pharmaceutical company Replek Farm Ltd. Skopje, Macedonia and Ciprofloxacin hydrochloride eye drops $3 \mathrm{mg} / \mathrm{ml}$ were purchased from a local pharmacy.

All the test solutions prepared from the active substances and pharmaceutical products used for examination were prepared in the respective mobile phase used for the chromatographic system.

Chromatographic methods used for both analytes in their pharmaceutical formulations were compendial, given in the monographs contained in British Pharmacopoeia BP 2012 (for ciprofloxacin hydrochloride) and British Pharmacopoeia (Veterinary) 2012 (for metronidazole), with slight modifications for experimental purposes. The modifications made are described in the following parts for each active substance, respectively. 
Implementation of modified pharmacopoeial HPLC methods for quality control in medicinal products

\section{RESULTS}

\section{Metronidazole Analysis}

Method used for examination of Metronidazole gel $0,75 \%$ was according to the Metronidazole monograph published in British Pharmacopoeia (Veterinary) 2012. It prescribes the use of: Spherisorb ODS $200 \mathrm{~mm} \times 4,6 \mathrm{~mm}$ column with $5 \mu \mathrm{m}$ particle size, column temperature $30^{\circ} \mathrm{C}$, mobile phase consisted of $30 \%$ methanol and $70 \%$ $10 \mathrm{mM}$ ammonium dihydrogen phosphate buffer, mobile phase flow rate $1,0 \mathrm{ml} / \mathrm{min}$, wavelength for UV detection $315 \mathrm{~nm}$ and injection volume of $10 \mu 1$. The chromatogram given in Figure 2 is obtained using the pharmacopoeial prepositions using Waters Spherisorb ODS2 $150 \mathrm{~mm}$ x 4,6 mm and $5 \mu \mathrm{m}$ particle size column, which is slightly shorter than the prescribed one, but within the permitted limits. The main peak with $\mathrm{RT}=3.857 \mathrm{~min}$ is from metronidazole and the other two smaller peaks are from its impurities.

Minor modifications in these prescribed chromatographic conditions were made in order to obtain better chromatographic parameters, better resolution and shorter run times. All the modifications made are within the allowed "Adjustments of chromatographic conditions" described in the European Pharmacopoeia, current edition (11).

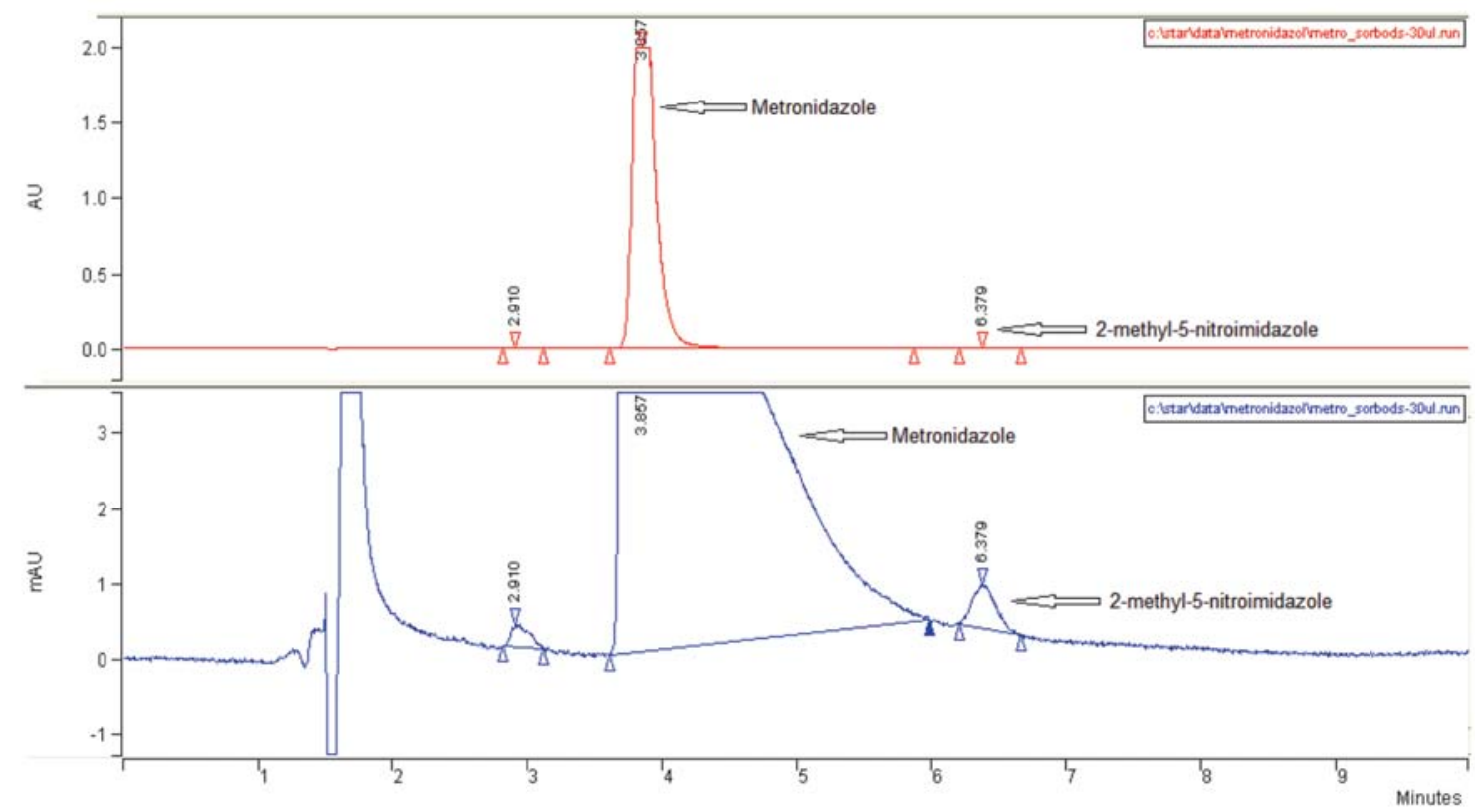

Figure 2. Chromatogram obtained according to the monograph given in British Pharmacopoeia (Veterinary) 2012 for quality control of active substance metronidazole. The lower chromatogram is extended X and Y-axis chromatogram from the upper full peak size chromatogram

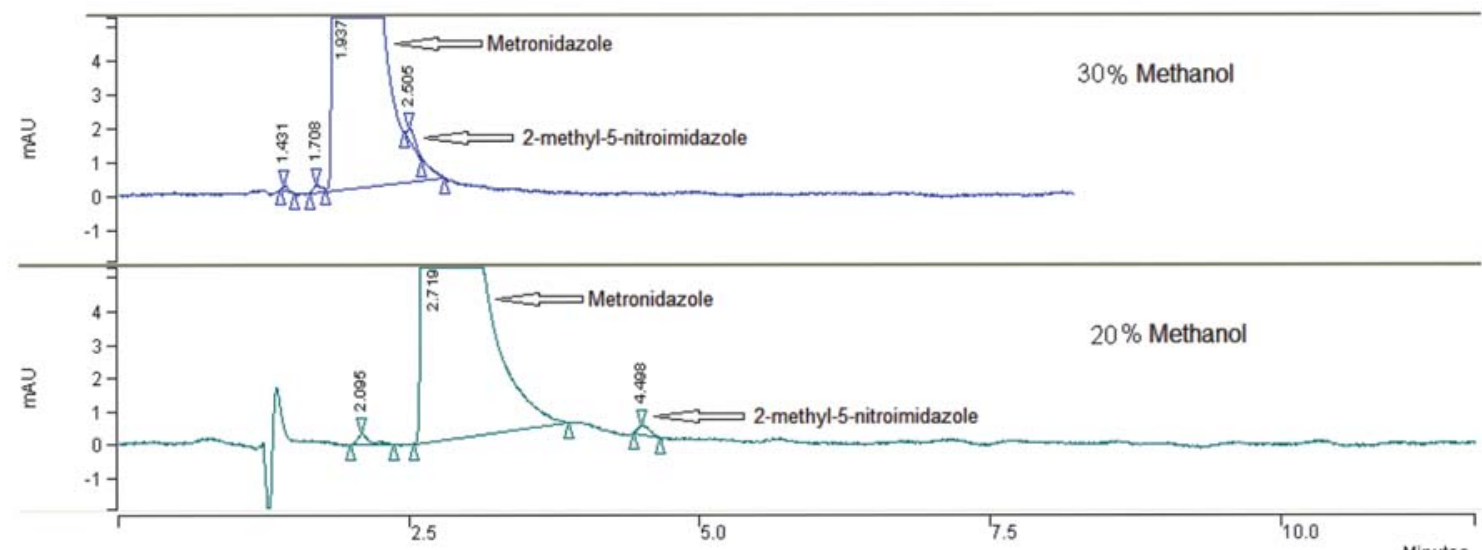

Figure 3. Mobile phase modification for achievement of satisfying retention of metronidazole and resolution between metronidazole and its specified impurity, 2-methyl-5-nitroimidazole 
Furthermore, with these slight changes in various parameters the system suitability criteria can still be satisfied without fundamentally modifying the pharmacopoeia prescribed method. For this purpose, a shorter chromatographic column was used, i.e. Discovery C18 $100 \mathrm{~mm} \times 4,6 \mathrm{~mm}$ column with $5 \mu \mathrm{m}$ particle size. Also, slight changes were made in the composition of the mobile phase. The concentration of methanol in the mobile phase was decreased from $30 \%(\mathrm{v} / \mathrm{v})$ as prescribed in the monograph to $20 \%$ $(\mathrm{v} / \mathrm{v})$. All other chromatographic conditions are the are present in Metronidazole gel formulation, and should be also quantified during quality control of this pharmaceutical product. It can easily be noticed that parabens cannot be quantified at $315 \mathrm{~nm}$ because they do not show any absorbance at this wavelength, whereas metronidazole absorbance decreases significantly at a wavelength of $254 \mathrm{~nm}$, which can be clearly noticed from 3-D contour diagram analysis in the middle part of Figure 4. This is due to their different spectral characteristics, which are shown in the bottom part of Figure 4.

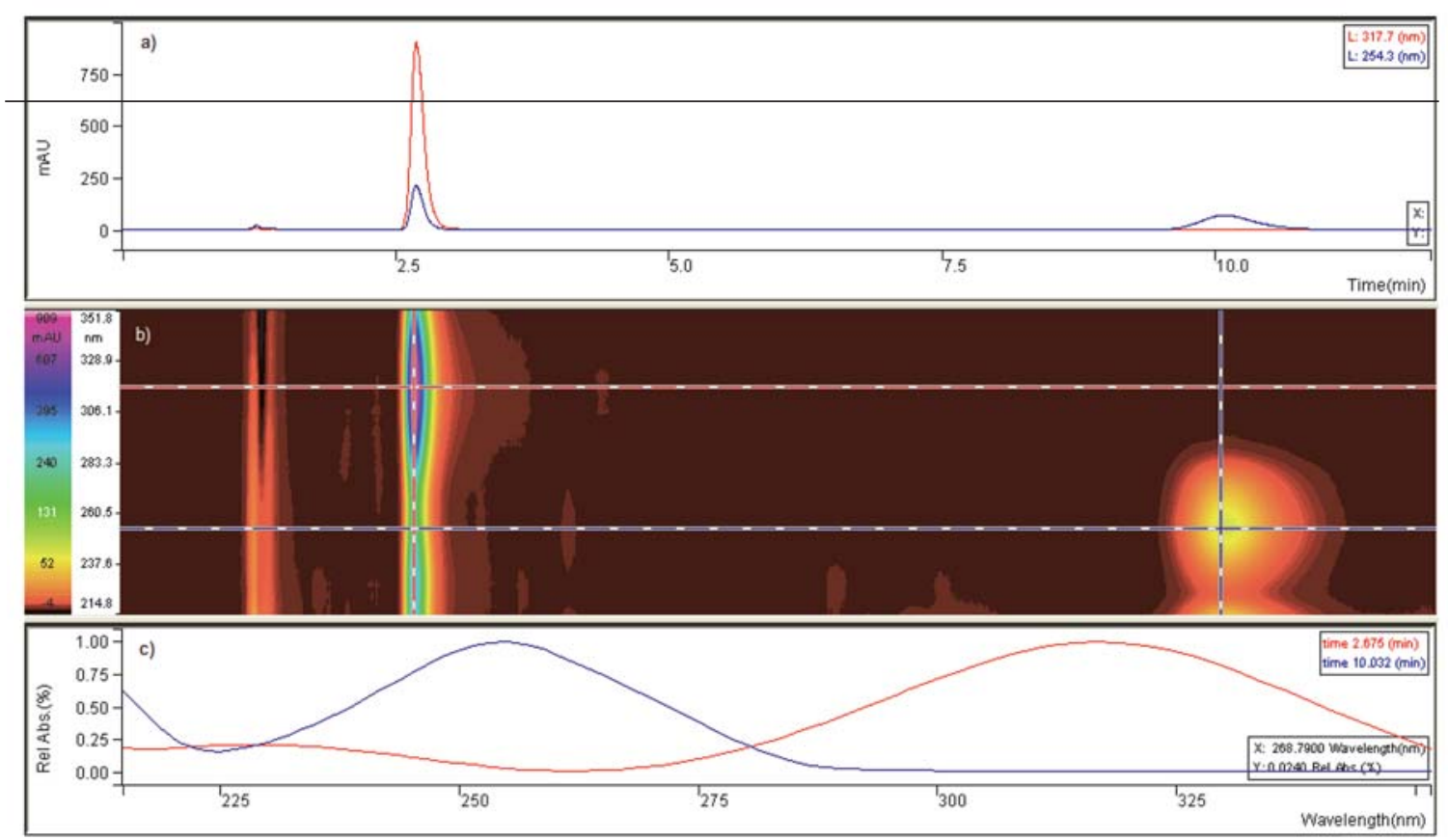

Figure 4. Simultaneous presentation of chromatogram at two wavelengths, $315 \mathrm{~nm}$ - red colored chromatogram and $254 \mathrm{~nm}$ - blue colored chromatogram (a ); 3-D contour diagram of chromatogram from Metronidazol gel (b) and UV spectrums of metronidazole - red colored spectrum and Nipagin - blue colored spectrum (c)

same as the above cited pharmacopoeial conditions. Presented chromatograms are from $0,5 \mathrm{mg} / \mathrm{ml}$ metronidazole working standard solution in mobile phase.

A test solution made of Metronidazole gel $0,75 \%$ dissolved in mobile phase, with the same concentration of metronidazole as in the standard solution $(0,5 \mathrm{mg} / \mathrm{ml})$, was examined at the same above described chromatographic conditions. One chromatogram, presented at 2 different wavelengths, is given in Figure 4. Both monitoring wavelengths are extracted from a PDA detector, and compare peak signals monitored at $315 \mathrm{~nm}$, wavelength prescribed for quantification of metronidazole, with the signals monitored at $254 \mathrm{~nm}$, wavelength prescribed for quantification of methylp-hydroxybenzoate (Nipagin) and propyl-phydroxybenzoate (Nipasol). These two preservatives
On the following two figures (Fig. 5 and Fig. 6), a real case of quality investigation is presented, where it can be seen that this modified pharmacopoeial method also successfully separates metronidazole and its specified impurity, 2-methyl5-nitroimidazole, in the pure active substance and also in the gel formulation. The UV spectral analysis (Fig. 6) illustrates the spectral characteristics of chromatogram peaks labeled with their retention times, and in this way contributes to qualitative analysis, i.e. for their identification and peak purity determination.

Additional changes were made to the chromatographic method for complete chemical assay determination of Metronidazole gel, including the active pharmaceutical ingredient (metronidazole) and formulation participants with preserving functions (Nipagin and Nipasol), in order to obtain 
Implementation of modified pharmacopoeial HPLC methods for quality control in medicinal products

shorter analysis times, and thus obtaining higher sample throughput in industrial quality control laboratories. The following changes were made: even shorter chromatographic column, RP Select B $75 \mathrm{~mm} \times 4 \mathrm{~mm}$ column with $5 \mu \mathrm{m}$ particle size was used, the composition of the used mobile phase was $55 \%(\mathrm{v} / \mathrm{v})$ methanol and $45 \%(\mathrm{v} / \mathrm{v})$ water and viewing wavelength $240 \mathrm{~nm}$. The test solution was prepared by dissolving $1 \mathrm{~g}$ of gel into $50 \mathrm{ml}$ mobile phase in mixture of methanol and water in ratio 1:5.

Since there is a significant decrease in the absorbance of metronidazole at $254 \mathrm{~nm}$, and of parabens at $315 \mathrm{~nm}$, the wavelength of $240 \mathrm{~nm}$ is chosen as a compromise for quantitative determination of both, the active substance and the preservatives within the formulation. This enables use even of older types of HPLC systems with single channel UV detectors, because the signal monitoring of all three components of interest is performed at one wavelength, $240 \mathrm{~nm}$, instead at two, $315 \mathrm{~nm}$ for metronidazole and $254 \mathrm{~nm}$ for preservatives.

All other chromatographic conditions are the same as the pharmacopoeial conditions cited at the beginning of this part. This method was tested also with $0.05 \%$ TFA at $\mathrm{pH}$ value of 2.15 as part of the mobile phase, instead of pure water, but a peak splitting of metronidazole was observed (Fig. 7). Test solution of Metronidazole gel was prepared with dissolving $\sim 1,0 \mathrm{~g}$ gel in $50 \mathrm{ml}$ mobile phase.

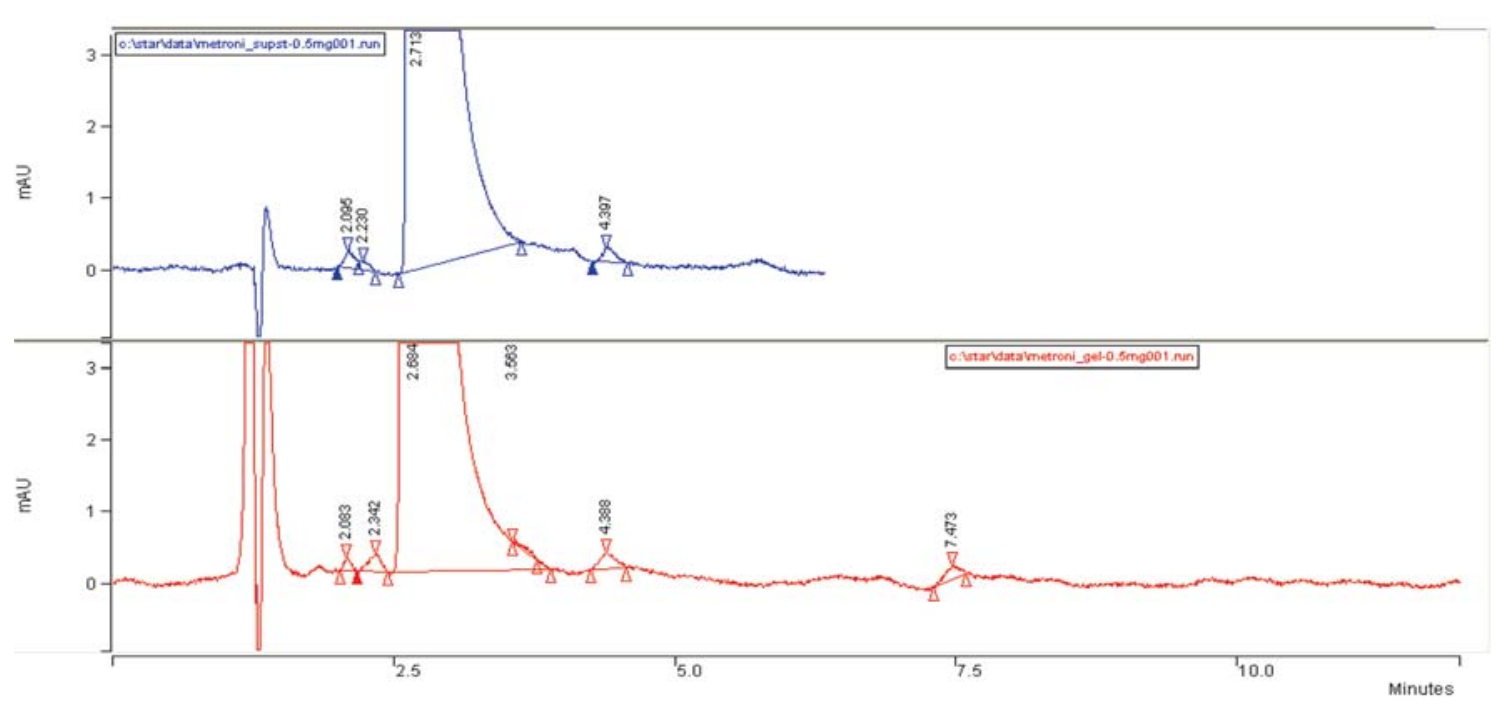

Figure 5. Comparison of chromatograms of active substance (blue chromatogram above) and gel-sample (red chromatogram below), monitored at $315 \mathrm{~nm}$. The peak with RT 4,4 min present on both hromatograms is the specified impurity 2-methyl-5-nitroimidazole

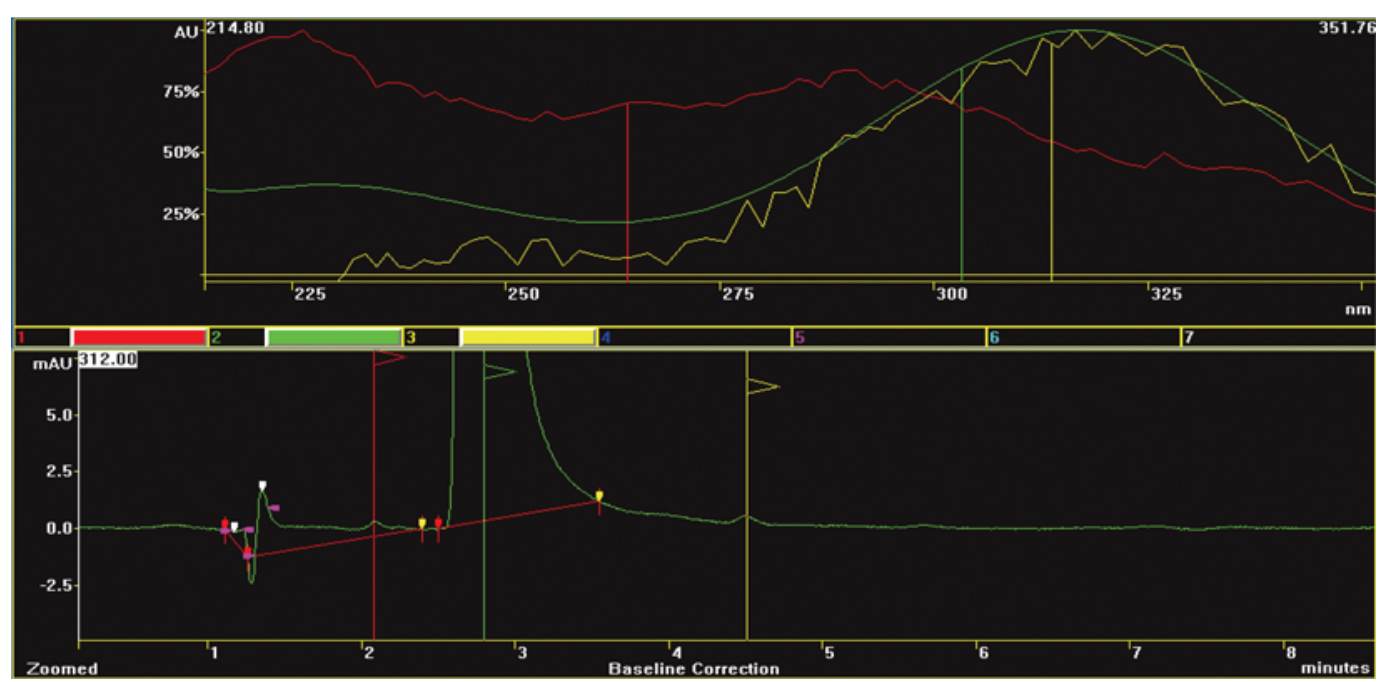

Figure 6. Spectral characteristics of impurities eluting in vicinity of metronidazole 


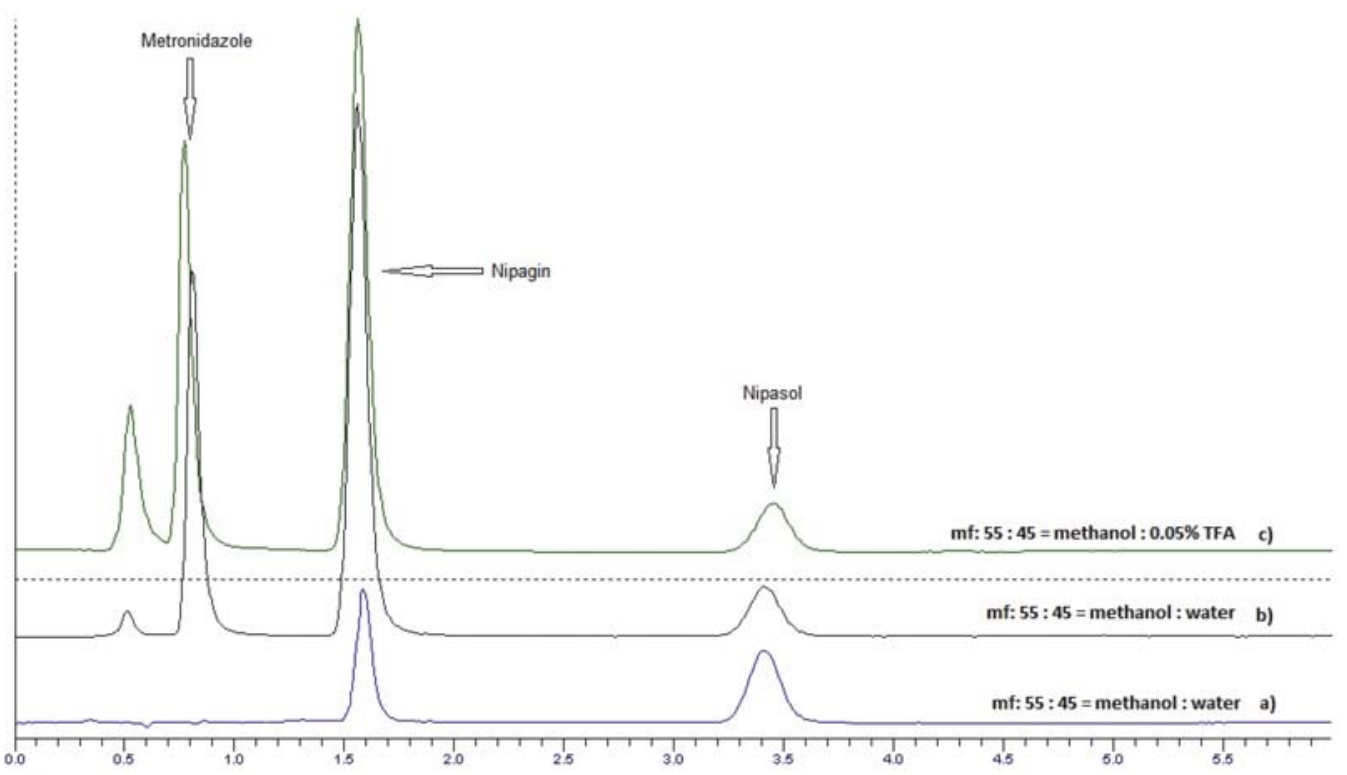

Figure 7. Determination of metronidazole, Nipagin and Nipasol using RP Select B $75 \mathrm{~mm} \times 4 \mathrm{~mm}$ with $5 \mu \mathrm{m}$ particle size HPLC column, at absorbance of $240 \mathrm{~nm}$, with different mobile phase composition as indicated in the figure; a) Paraben mixture; b) and c) Metronidazol gel

The chromatogram a) on Figure 7 shows separation times of standards of preservatives Nipagin and Nipasol without presence of the active substance, metronidazole. The next chromatogram above this one, chromatogram b) is from a sample of Metronidazol gel, containing both parabens and active pharmaceutical substance, obtained with mobile phase composed of water and methanol.
The last chromatogram c), at the top, illustrates separation problem occurred during use of $0.05 \%$ trifluoroacteic acid with $\mathrm{pH}=2.15$ instead of water, which yields metronidazole peak splitting probably induced by acidity of mobile phase which is in vicinity of the $\mathrm{pKa}$ value of metronidazole, which equals 2.6 (16). It can be clearly seen that the peak of metronidazole in this chromatogram is wider
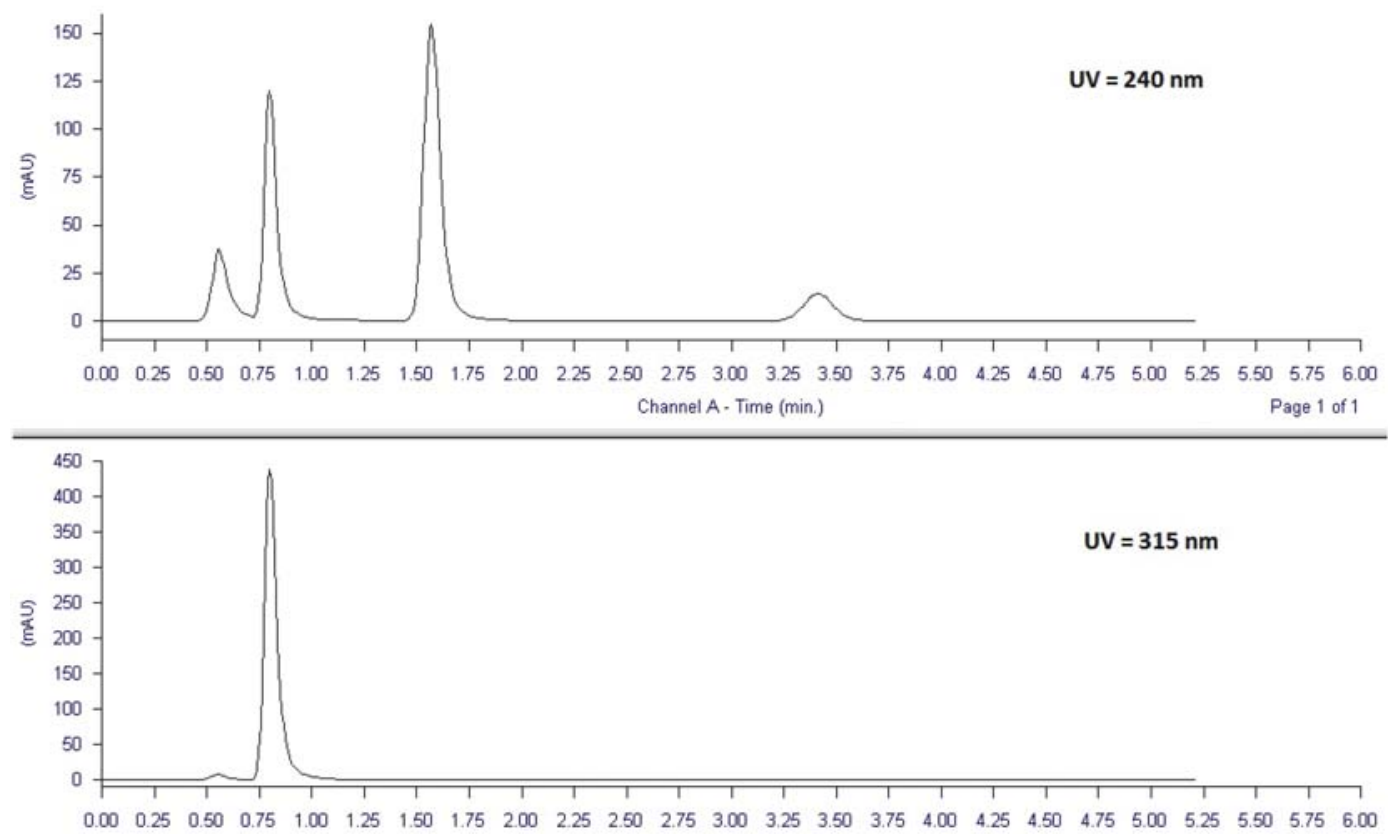

Figure 8. Ruggednes testing of method with other HPLC system, Perkin Elmer Series 200. Monitoring at $240 \mathrm{~nm}$ and at $315 \mathrm{~nm}$ 
Implementation of modified pharmacopoeial HPLC methods for quality control in medicinal products

than the same peak in the chromatogram below this one in the same figure, which means that at this $\mathrm{pH}$ value metronidazole starts to ionize. But there is also something from the gel formulation that elutes at the same time as the split peak. This can also be seen from the comparison of the chromatograms b) and c): first peak in the chromatogram b) obtained with water is much smaller than the first peak in the chromatogram c), obtained with $0.05 \%$ trifluoroacteic acid with $\mathrm{pH}=2.15$. The first small peak in the chromatogram b) originates from the gel formulation, whereas the first peak in the chromatogram c) is a combination of gel formulation ingredients and the active substance, which is also confirmed by spectral analysis. The performed spectral analysis showed that it contains several spectral lines and the peak is not pure. That is why we excluded this type of mobile phase from our investigation.

This method was also tested for ruggedness by performing it on another, different type of HPLC instrument, Perkin Elmer Series 200 with quaternary low-pressure mixing pump and dual beam PDA detector, compared with previous analysis which were performed on Varian ProStar with ternary high-pressure mixing pump and single beam PDA detector. Obtained chromatographic separations with both systems were satisfactory,

Table 1. Summary of method validation study

\begin{tabular}{|c|c|c|c|c|}
\hline \multirow{2}{*}{$\begin{array}{l}\text { Analytical technique } \\
\text { Apparatus }\end{array}$} & & \multicolumn{3}{|l|}{ HPLC } \\
\hline & & \multicolumn{3}{|c|}{ Varian ProStar HPLC with PDA detector } \\
\hline \multirow{2}{*}{ Validation parameters } & \multirow{2}{*}{$\begin{array}{l}\text { Acceptance criteria } \\
\text { (17) }\end{array}$} & \multicolumn{3}{|c|}{ Results } \\
\hline & & Metronidazole & Nipagin & Nipasol \\
\hline RANGE: & $\begin{array}{l}\text { min. accepted conc. } \\
80-120 \%\end{array}$ & $\begin{array}{l}0,105-0.195 \\
\text { Metronidazole / } \mathrm{mL} \\
(70-130 \%)\end{array}$ & $\begin{array}{l}0,035-0.065 \\
\text { Nipagin / mL } \\
(70-130 \%)\end{array}$ & $\begin{array}{l}0,007-0.013 \\
\text { Nipasol } / \mathrm{mL} \\
(70-130 \%)\end{array}$ \\
\hline $\begin{array}{l}\text { LINEARITY: } \\
\text { Correlation coefficient } \mathrm{R}^{2} \text { : }\end{array}$ & $\geq 0,9900$ & $\mathrm{R}^{2}=0,9999$ & $\mathrm{R}^{2}=0,9999$ & $\mathrm{R}^{2}=0,9997$ \\
\hline $\begin{array}{l}\text { ACCURACY: } \\
\text { Recovery: }\end{array}$ & $98,0-102,0 \%$ & Recovery $=99.28 \%$ & Recovery $=100.15 \%$ & Recovery $=98,71 \%$ \\
\hline $\begin{array}{l}\text { PRECISION: } \\
\text { System repeatability }\end{array}$ & $\mathrm{RSD} \leq 2,0 \%$ & $\mathrm{RSD}=0.0003 \%$ & $\mathrm{RSD}=0.002 \%$ & $\mathrm{RSD}=0.0991 \%$ \\
\hline Method repeatability & $\mathrm{RSD} \leq 2,0 \%$ & $\mathrm{RSD}=1,85 \%$ & $\mathrm{RSD}=1,52 \%$ & $\mathrm{RSD}=1,64 \%$ \\
\hline
\end{tabular}

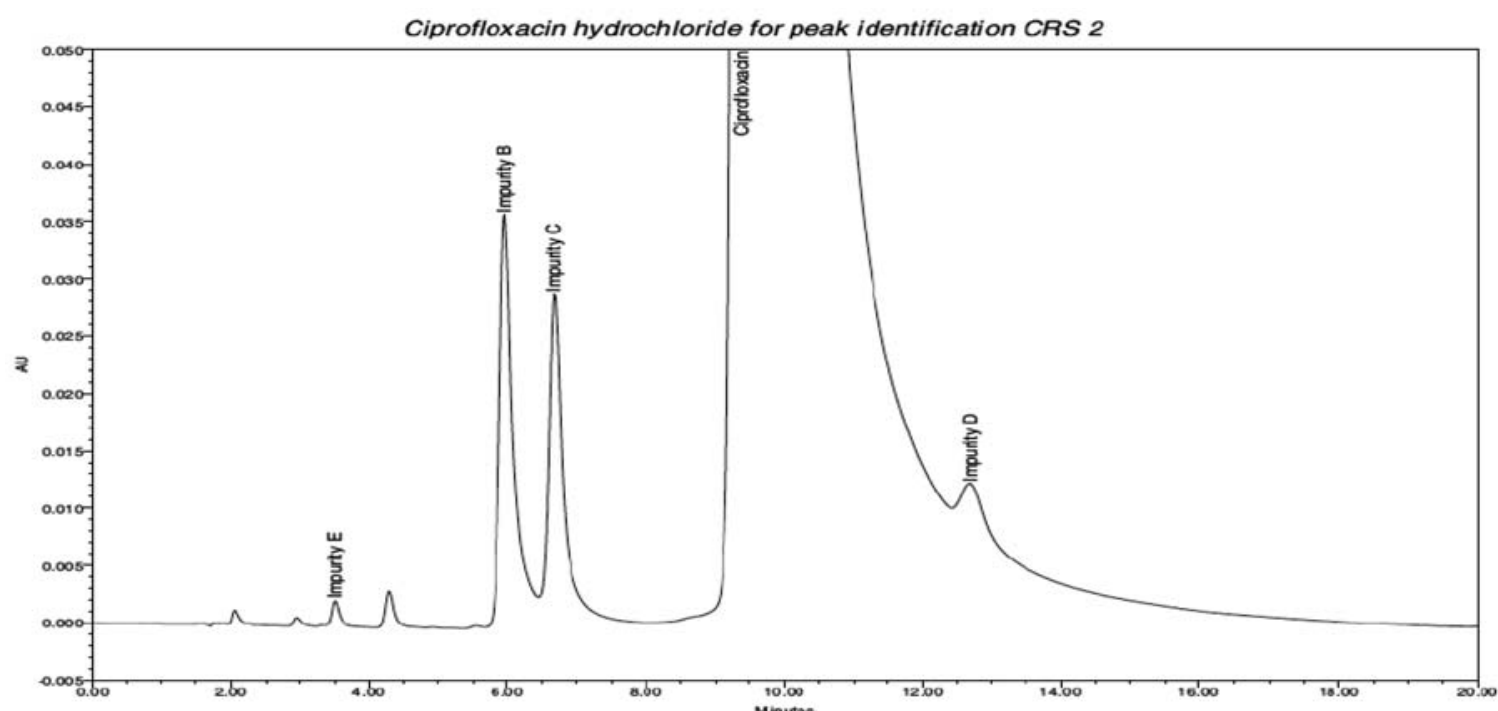

Figure 9. Chromatogram of solution for peak identification of ciprofloxacin impurities obtained using conditions prescribed in British Pharmacopoeia monograph, originating originally from the pharmacopoeia itself 
and the chromatogram obtained from the analysis performed on Perkin Elmer series 200 is presented on Figure 8.

Summary of the method validation for simultaneous quantitative determination of metronidazole and both parabens, present in the gel formulation is presented in Table 1 .

\section{Ciprofloxacin Analysis}

The method used for examination of Ciprofloxacin film coated tablets $500 \mathrm{mg}$ and Ciprofloxacin eye drops $3 \mathrm{mg} / \mathrm{ml}$ was according to Ciprofloxacin hydrochloride monograph given in British Pharmacopoeia 2012. It prescribes the use of: Nucleosil C18 $250 \mathrm{~mm} \times 4,6 \mathrm{~mm}$ column with $5 \mu \mathrm{m}$ particle size, column temperature $40^{\circ} \mathrm{C}$, mobile phase consisted of 13 volumes of acetonitrile and $87 \%$ 2,45 g/l phosphoric acid R, previously adjusted to $\mathrm{pH} \mathrm{3,0}$ with triethylamine, mobile phase flow rate $1,5 \mathrm{ml} / \mathrm{min}$, wavelength for UV detection $278 \mathrm{~nm}$ and injection volume of $10 \mu \mathrm{l}$. The chromatogram obtained using this pharmacopoeia prescribed conditions is presented in Figure 9.
Some minor modifications in this prescribed chromatographic conditions were made: a shorter chromatographic column was used, Discovery C18 $100 \mathrm{~mm} \times 4,6 \mathrm{~mm}$ column with $5 \mu \mathrm{m}$ particle size and thus the mobile phase flow rate was also decreased to $1,2 \mathrm{ml} / \mathrm{min}$. Temperature was decreased to $30{ }^{\circ} \mathrm{C}$. All modif cations made are within the allowed "Adjustments of chromatographic conditions" described in the European Pharmacopoeia, current edition. Ph. Eur./BP, current editions, under General Notices Part III, General Notices of the European Pharmacopoeia, 1.1. General Statements, under "Validation of Pharmacopoeial Methods" states:

"The test methods given in monographs and general chapters have been validated in accordance with accepted scientific practice and current recommendations on analytical validation. Unless otherwise stated in the monograph or general chapter, validation of the test methods by the analyst is not required." $(8,11)$.

Furthermore, with these slight changes in various parameters the system suitability criteria can still be satisfied without fundamentally modifying the pharmacopoeia prescribed method.

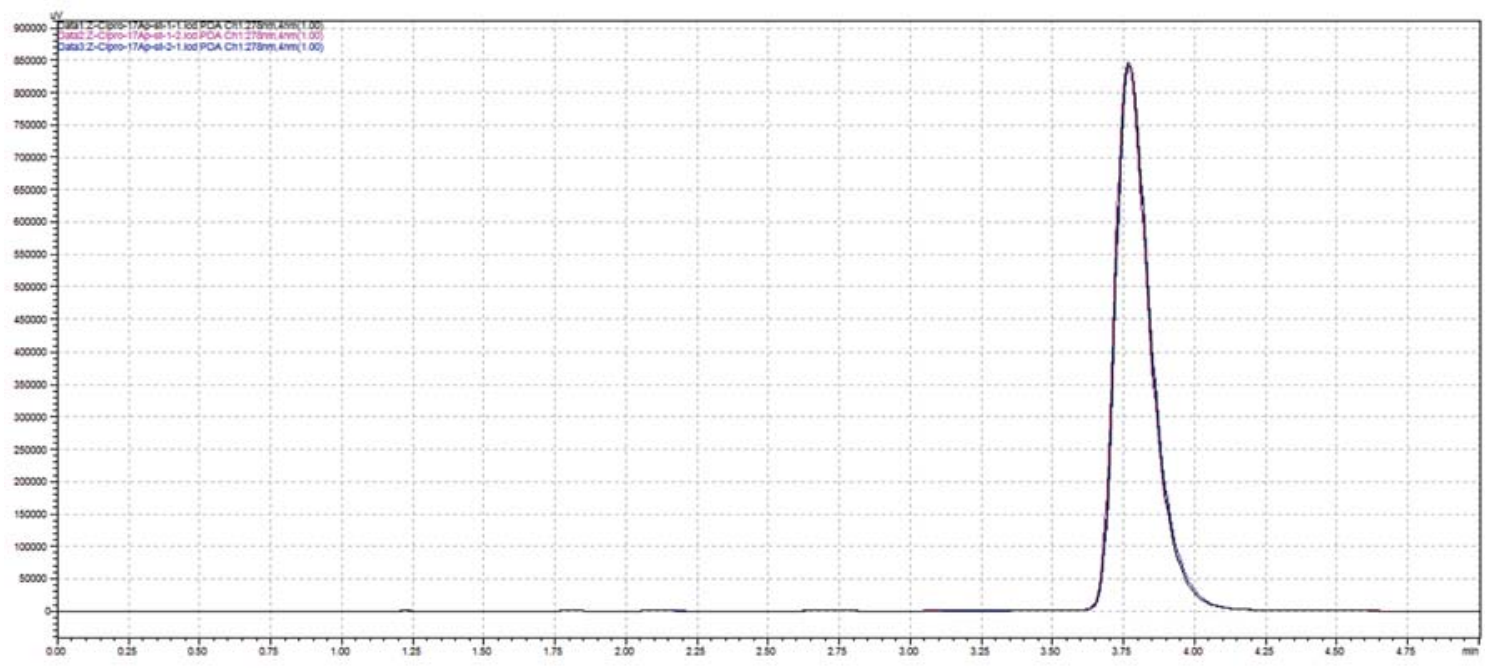

Figure 10. Overlaid chromatograms of three consecutive injections of ciprofloxacin hydrochloride working standard solution with concentration of $0,5 \mathrm{mg} / \mathrm{ml}$

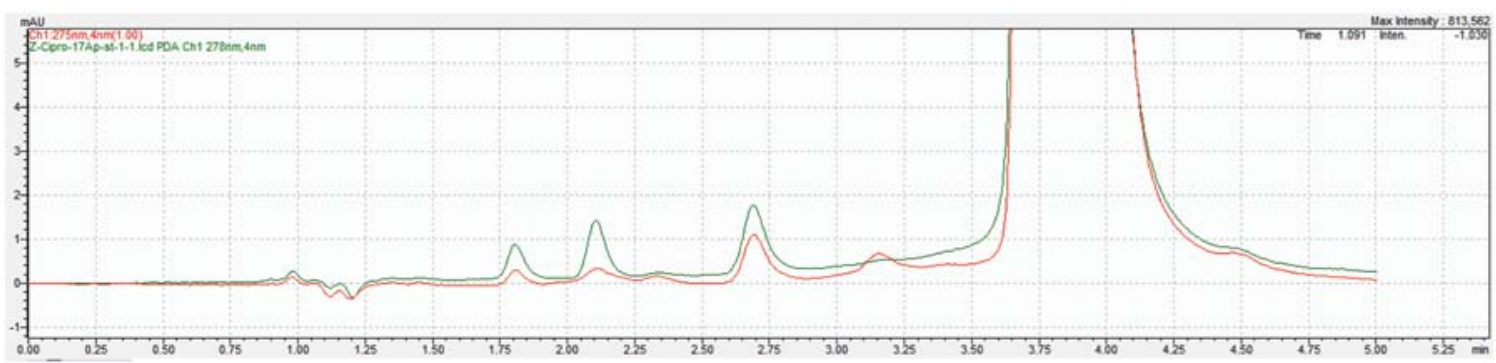

Figure 11. Demonstrative chromatograms with satisfying separation and resolution between active substance, ciprofloxacin hydrochloride and its impurities in chromatograms of standard solution for peak identification (red coloured chromatogram) and Ciprofloxacin film coated tablets test solution (green coloured chromatogram) 
Implementation of modified pharmacopoeial HPLC methods for quality control in medicinal products

In Figure 10, the full size and shape of ciprofloxacin peak in 3 consecutive standard solution injections can be seen. Figure 11 illustrates expanded views of chromatograms of sample, film coated tablets solution and peak identity solution, in PDA overlay mode. Thus, an optimal retention of the active substance ciprofloxacin hydrochloride and good resolution between the active substance and its impurities, were achieved. The repeatability of this chromatographic method is excellent which can be seen from the three consecutive, overlaid injections presented on Figure 10. Presented chromatograms are from $0.5 \mathrm{mg} / \mathrm{ml}$ ciprofloxacin hydrochloride working standard solution and Ciprofloxacin film coated tablets test solution, in mobile phase.

Ciprofloxacin eye drops $5 \mathrm{mg} / \mathrm{ml}$ were prepared in the same way, with the same concentration of the active ingredient in the test solution and were tested under the same above described chromatographic conditions. The obtained complete PDA record is presented in Figure 12. It can be seen that the main peak of the active substance is well separated from the other peaks present in the chromatogram, originating from all related substances or formulation excipients. The left top part is a contour or 3-D chromatogram, below is the extracted chromatogram at $278 \mathrm{~nm}$ with peak report on the bottom left side. The right upper diagram is UV spectrum of ciprofloxacin and below is a peak purity graphic and presentation with calculation.

In the following figure, (Fig. 13), an expanded overlay comparison of two chromatograms is presented, one is of the solution for peak identification of specified impurities of

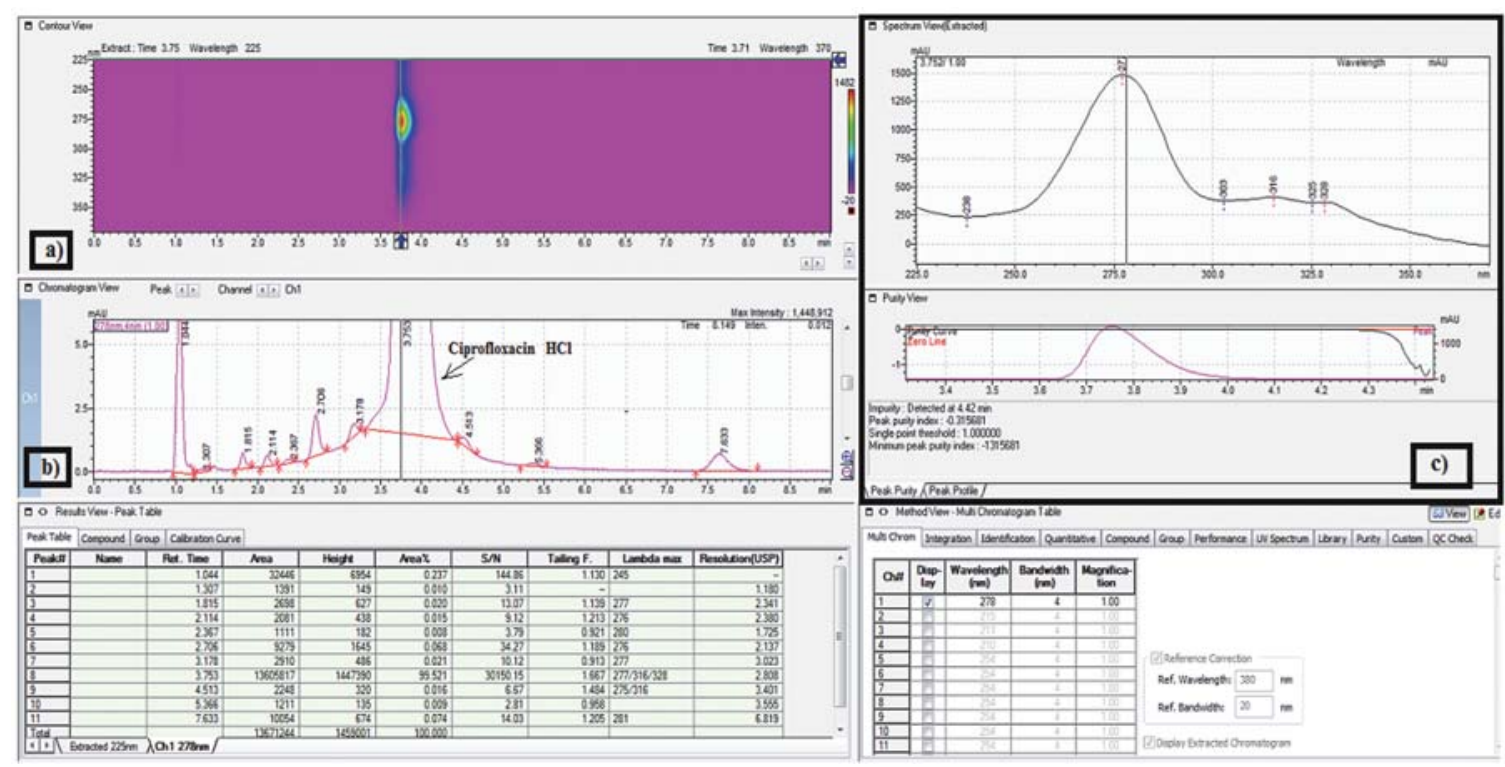

Figure 12. Presentation of: 3D or contour diagram (a) and spectra of the main peak of the active substance and peak purity of the same (c) from chromatogram of test solution prepared from Ciprofloxacin eye drops (b) with the obtained results presented in the table given below the chromatogram

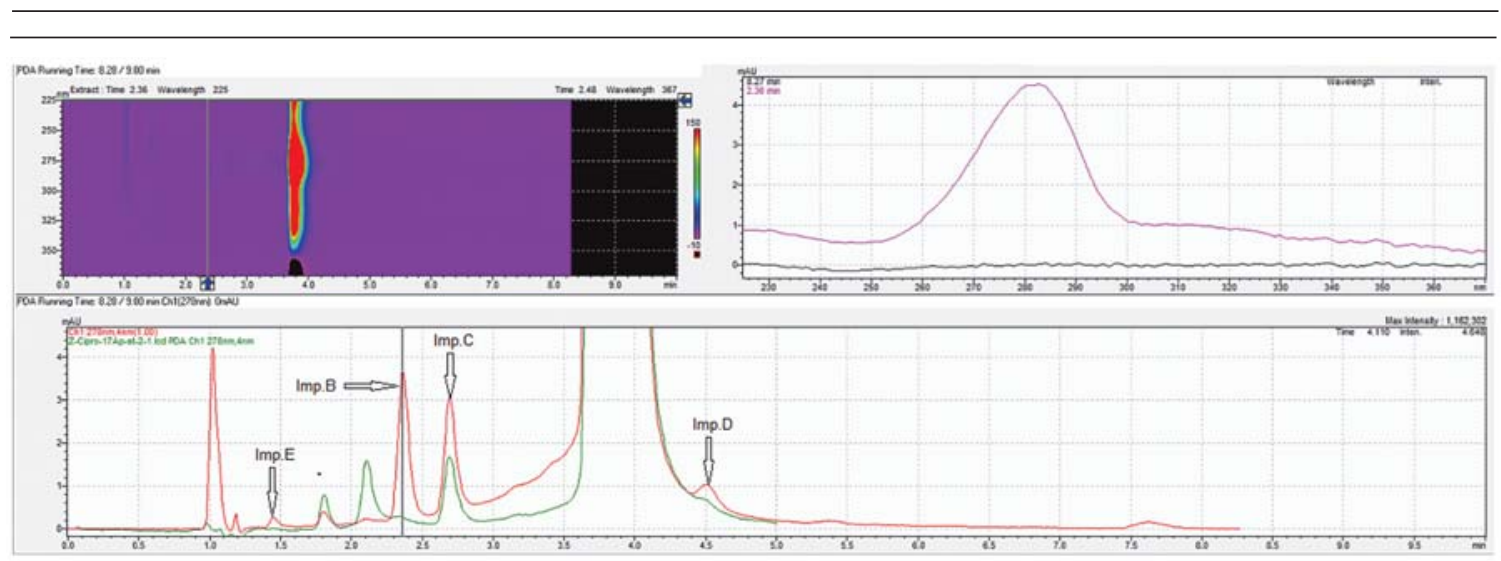

Figure 13. Comparison of chromatograms of solution for peak identification of specified impurities of ciprofloxacin (red colored chromatogram) and from Ciprofloxacin eye drops test solution (green colored chromatogram) 
ciprofloxacin, for determination and quantification of its impurities (red colored chromatogram) and the other is from the test solution prepared from Ciprofloxacin eye drops (green colored chromatogram).

\section{DISCUSSION}

\section{Metronidazole Analysis}

Optimization of the pharmacopoeia prescribed method for quality control of metronidazole active substance led to achievement of better chromatographic parameters, better resolution and shorter run times, when compared to the results obtained using the original unmodified pharmacopoeial method, which can be clearly seen from Figure 2 and Figure 3.

Using a shorter chromatographic column we succeeded to achieve satisfying, optimal retention of metronidazole during shorter run times. The main reason for lowering methanol percentage in the mobile phase composition was obtaining better separation and better resolution, using this shorter column, between metronidazole (main peak in the chromatograms given on Figure 3) and its specified impurity, 2-methyl-5-nitroimidazole (peak with RT $\sim 2,5$ on the first and RT $\sim 4,5$ on the second chromatogram on the figure), which is presented on Figure 3. Thus, it is proved that this specified impurity will not interfere during assay determination of active component, and the quantity of the same, if present, can also be determined.

This modified pharmacopoeial method can also be used for quality control of Metronidazole gel, because as it is shown on Figure 4, a good separation and resolution between Metronidazole and two parabens in the composition of the gel formulation is obtained and therefore it can be used for their simultaneous determination using 240 $\mathrm{nm}$ as monitoring wavelength or dual wavelength monitoring at $315 \mathrm{~nm}$ for Metronidazole and 254 $\mathrm{nm}$ for Nipagin and Nipasol.

Further, Figure 5 and Figure 6 show that not only this method can be used for quantification of the constituents present in Metronidazole gel formulation, it can also serve for identification and quantification of metronidazole impurities, if present. Their determination can be performed directly in test solution prepared from the Metronidazole gel formulation, without any interference from the excipients present in the gel formulation.

The other, newly developed method for assay determination of Metronidazole gel, is even better for routine analysis of numerous samples in 40 quality control laboratories within pharmaceutical industries. Use of an even shorter column $(75 \mathrm{~mm}$ instead of $100 \mathrm{~mm}$ ) with different properties from the previous one (C8 instead of C18) and different, more simple mobile phase (composed only of methanol and water instead of buffer), emphasizes the numerous benefits that this method has, when compared to the pharmacopoeial one and other methods developed for this purpose. For comparison: Tashtoush B. M., Jacobson E. L. and Jacobson M. K. developed a method for HPLC determination of Metronidazole in dermatological formulations, using 0,01\% trifluoroacetic acid and acetonitrile as mobile phase constituents, but the separation was accomplished during longer run times, $\sim 10$ minutes (18). When a $0.15 \%$ TFA was used as a constituent of the mobile phase, instead of water, a peak splitting of metronidazole was observed, probably because of the close values of $\mathrm{pH}$ of the mobile phase $(\mathrm{pH}=2.15$ of the inorganic part) and $\mathrm{pKa}$ value of metronidazole which equals 2.6. Other authors (Melikyan et al.) with regards to the development of a method for determination of metronidazole benzoate and related impurities in bulk and in pharmaceutical formulations, prescribe the use of CN-RP column and mobile phase composed of acetonitrile and $0.1 \%$ octansulfonic acid sodim salt; this method also needs longer run times, $\sim 15$ minutes (19).

All the changes we made during the development of our method proved to be beneficial and the goals were achieved: separation of the three main components of Metronidazole gel is successful with satisfying resolution between them and all of this can be achieved within run time of only 4,5 minutes, as can be seen from Figure 7 and Figure 8 . Results obtained from the performed validation of the developed method are presented in Table 1 and are in accordance with the ICH requirements for the tested validation parameters.

\section{Ciprofloxacin Analysis}

Minor modifications made to the pharmacopeial method for quality control of ciprofloxacin hydrochloride, i.e. usage of shorter C18 chromatographic column $(100 \mathrm{~mm})$ instead of the prescribed one $(250 \mathrm{~mm})$, with slight optimization of the mobile phase flow rate $(1.2 \mathrm{ml} / \mathrm{min}$ instead of $1.5 \mathrm{ml} / \mathrm{min}$ ), led to optimization of the retention time of ciprofloxacin hydrochloride, achieving shorter run times (even $\sim 4$ times shorter when compared to the pharmacopoeial method), but still preserving the good resolution between ciprofloxacin hydrochloride and its impurities. This method was also proven to be useful in assay determination and identification and quantification of ciprofloxacin impurities for quality control of two pharmaceutical dosage forms 
Implementation of modified pharmacopoeial HPLC methods for quality control in medicinal products

containing ciprofloxacin: Ciprofloxacin eye drops and Ciprofloxacin film coated tablets. Excipients present in these formulations do not interfere with the active substance nor with its impurities.

\section{CONCLUSION}

As it can be clearly seen from the above presented results from the conducted research, some modifications of the pharmacopoeial methods for quality control of active substances metronidazole and ciprofloxacin led to creation of simple, fast, and reliable methods for analysis of veterinary pharmaceutical preparations containing these two active substances.

The above described, slightly modified and optimized pharmacopoeial methods for quality control of Metronidazole gel and Ciprofloxacin film coated tablets and eye drops can be successfully applied in laboratories for quality control of veterinary medicines, for assay determination and identification and quantification of specified impurities.

The new method developed for simultaneous assay determination of the active substance and the both preservatives in Metronidazole gel is simple, faster and more ecological (less methanol and time consumption) and less expensive than the compendial analytical method.

With this work we aim to prompt the establishment of laboratories for quality control of veterinary medicines sold in veterinary pharmacies and ambulances in our country and the implementation of the existing regulations for testing veterinary medicines.

\section{REFERENCES}

1. Official Journal of European Union. Commission Regulation (EU) No 37/2010 of 22 December 2009 on pharmacologically active substances and their classification regarding maximum residue limits of foodstuffs of animal origin. Pub. L. No. 15/72 (January 20, 2010).

2. WedgewoodPetRx.com [Internet]. New Jersey (USA): Wedgewood Pharmacy; c2004-13 [cited 2014 May 04]. Available from: http://www.wedgewoodpetrx.com/

3. PetMD [Internet]. Pennsylvania (USA): Pet360, Inc.; c1999-2014 [cited 2014 May 04]. Available from: http://www.petmd.com/

4. Official Journal of European Communities. Directive 2001/82/EC of the European Parliament and of the Council of 6 November 2001 on the Community code relating to veterinary medicinal products. Pub. L. No. 311/1-66 (November 28, 2001).
5. Official Journal of European Communities. Directive 2004/28/EC of the European Parliament and of the Council of 31 March 2004 on the Community code relating to veterinary medicinal products. Pub. L. No. 136/58-84 (April 30, 2004).

6. Veterinary EU Legislation: Medicines [Internet]. Brussels (EU): Federation of Veterinarians of Europe (FVE); c2014 [cited 2014 May 07]. Available from: http://www.fve.org/veterinary/medicines.php\#1

7. Veterinary medicines: regulatory information [Internet]. London (UK): European Medicines Agency; c1995-2014 [cited 2014 May 07]. Available from:

http://www.ema.europa.eu/ema/index.jsp? curl= pages/regulation/landing/veterinary_medicines regulatory.jsp\&mid=

8. British Pharmacopoeia Commission. British Pharmacopoeia (Veterinary) 2012. Norwich: The Stationery Office; 2011.

9. China Veterinary Pharmacopoeia Commission. Veterinary Pharmacopoeia of the People's Republic of China. 2010 ed. Beijing: China Agriculture Press; 2010.

10. Indian Pharmacopoeia 2014: Veterinary monographs. $7^{\text {th }}$ ed. Raj Nagar, Ghaziabad: Indian Pharmacopoeia Commission; 2014.

11. European Pharmacopoeia. $7^{\text {th }}$ ed. Strasbourg: European Directorate for the Quality of Medicines Council of Europe; 2010-2012.

12. British Pharmacopoeia Commission. British Pharmacopoeia 2012. Norwich: The Stationery Office; 2011.

13. United States Pharmacopeia and National Formulary (USP 33-NF 28). Rockville: United States Pharmacopeia Convention; 2009.

14. Society of Japanese Pharmacopoeia. Japanese Pharmacopoeia. $16^{\text {th }}$ ed. Tokyo: Maruzen Company, Ltd.; 2012.

15. The International Pharmacopoeia. $4^{\text {th }}$ ed. Geneva: World Health Organization; 2006.

16. Product Monograph. Flagyl ${ }^{\circledR}$ (Metronidazole) $10 \%$ w/w Cream, $500 \mathrm{mg}$ Capsules. Quebec: SanofiAventis Canada Inc.; 2013.

17. International Conference on Harmonization of Technical Requirements for Registration of Pharmaceuticals for Human Use; ICH Harmonised Tripartite Guideline. Validation of Analytical Procedures: Text and Methodology Q2(R1), Current Step 4 version, Parent Guideline dated 27 October 1994 [cited 2014 Oct 07]. Available from: http://www.ich.org/fileadmin/Public_Web_Site/ICH Products/Guidelines/Quality/Q2_R1/Step4/Q2_R1 Guideline.pdf 
18. Tashtoush, BM., Jacobson, EL., Jacobson, MK. (2008). Validation of a simple and rapid HPLC method for determination of metronidazole in dermatological formulations. Drug Dev Ind Pharm. 34(8): 840-844. http://dx.doi.org/10.1080/03639040801928598 PMid:18618307
19. Melikyan, AL., Martirosyan, SS., Grigoryan, SR., Topchyan, VH., Davtyan, KT. (2013). Development and validation of HPLC method for the determination of metronidazole benzoate and related impurities in bulk and pharmaceutical formulations. IJPSR. 4(7): 2594-2599.

Please cite this article as: Piponski M., Bakovska T., Naumoska M., Rusevska T., Trendovska Serafimovska G., Andonoska H. Preliminary investigation of the possibility for implementation of modified pharmacopoeial HPLC methods for quality control of metronidazole and ciprofloxacin in medicinal products used in veterinary medicine. Mac Vet Rev 2015; 38(1):31-42. http://dx.doi.org/10.14432/j.macvetrev.2014.11.029 